\section{Children's Performance on a Spatial Analogies Task}

\author{
Dedre Gentner \\ University of Washington
}

\begin{abstract}
GentNer, Dedre. Children's Performance on a Spatial Analogies Task. Child Development, $1977,48,1034-1039$. Young children performed as well as or better than adults on tasks requiring use of spatial analogies. The tasks involved body-parts analogies, such as, "If this [pictured] mountain had a knee, where would it be?" The entities referred to were physical objects familiar to young children, and this question format clearly called for analogical responding. Thus, sources of confusion were minimized. In a pilot study, it was shown that preschool children could apply such body-parts analogies to pictures as consistently as adults. The mappings were then made more difficult by varying the orientation of the pictured objects or by adding misleading pictorial details to the pictured objects. Adults performed somewhat less consistently than preschoolers and first graders when misleading details were present; there were no age differences when orientation was varied. These results suggest that analogical ability is present at a very early age.
\end{abstract}

The development of metaphorical and analogical ability is not well understood. On the one hand, very young children produce many seemingly metaphorical utterances (Bloom 1973; Carlson \& Anisfeld 1969; Chukovsky 1968). An example is a 15-month-old girl who used "moon" to refer not only to the real moon but also to such diverse objects as a half-grapefruit and a hangnail (Bowerman 1976). Recent work by Thomson and Chapman (Note 1) indicates that not all early overextensions are errors in stored word meanings, opening the possibility that at least some of them are metaphorical. On the other hand, experimental research on metaphor suggests that metaphorical ability is acquired late in development, after the acquisition of basic language skills (Asch \& Nerlove 1960; Inhelder \& Piaget 1958; Jacobson 1960; Kogan, Note 2; Winner, Note 3; Winner $\&$ Rosenstiel, Note 4). The plan of this paper is, first, to discuss some problems with the previous research; second, to propose an alternative approach based on an analysis of the mapping process underlying metaphor and analogy; and third, to describe a study based on this approach.
Studies of metaphorical development typically have utilized rather complex tasks; children are asked to produce or select a metaphor appropriate to a given context, or to explain a metaphor presented by the experimenter. Performance on these tasks increases over the age range of roughly 6 years to adolescence. However, factors other than metaphorical ability contribute to this trend. The first of these factors is prelearning of familiar metaphors. Many of the metaphors used in these studies occur frequently enough to allow prelearning of their metaphorical interpretations. For example, the term "sweet" as applied to a person can be understood by simple retrieval of the prelearned meaning of "sweet" as applied to people rather than being metaphorically interpreted from knowledge of the term "sweet" as applied to flavors. When familiar metaphors are used in an experiment, older children may perform better than younger children because of greater vocabulary experience and not because of greater metaphorical or analogical ability. A second factor is the child's conceptual knowledge, or lack of knowledge, of the domain from which the metaphor is taken and

I thank Albert Stevens, who collaborated in developing the model and the experimental paradigm, Andrew Meltzoff and Donald Norman for their helpful comments on earlier drafts of this paper, and Cheryl Roald for her help in devising stimuli and in testing subjects. I also thank the staff and teachers of the University of Washington Preschool, Temple Day Care Center, and Decatur Elementary School, Seattle, for their cooperation. Requests for reprints should be addressed to Dedre Gentner, Bolt Baranek and Newman, Inc., 50 Moulton Street, Cambridge, Massachusetts 02138.

[Child Development, 1977, 48, 1034-1039. (C) 1977 by the Society for Research in Child Development, Inc. All rights reserved.] 
I Development in tasks requirin If this [pictured Il objects familiar sponding. Thus, ol children could spings were then lding misleading istently than pre$o$ age differences present at a very

development complex tasks; ce or select a in context, or to by the experitasks increases bly 6 years to ors other than e to this trend prelearning of the metaphors zuently enough retaphorical ine term "sweet" understood by ned meaning of le rather than rpreted from $\mathrm{t}$ " as applied to cors are used in $\mathbf{n}$ may perform $e n$ because of :e and not beI) or analogical child's concepowledge, of the hor is taken and

the experimental $n$ earlier drafts of jects. I also thank Care Center, and nts should be adreet, Cambridge

ppment, Inc, All rights of the domain in which it is applied. For example, young children may not know the culturally agreed-upon systems of personality traits and emotional states that must be used in order to apply such metaphors as "hard/soft" or "sweet/bitter" to people. Their inappropriate use of such metaphors may stem not from lack of metaphorical ability but from lack of the conceptual knowledge necessary to correctly apply that ability.

A third factor that must be controlled is the child's understanding of the invitation to use metaphor. Young children given a question like "Can a person be sweet?" may be more likely than older children to assume that their literal knowledge of word meaning is being called into question, and to respond literally even if they are capable of metaphorical responding. Thus, nonmetaphorical responses may stem from misinterpretation of the task. Finally, much of the previous work on metaphor has required subjective judgments in order to convert the subject's responses into some classificatory scheme such as "metaphorical/literal/thematic" or "appropriate/inappropriate." This subjective step may be necessary for certain questions, but it opens the possibility of an adult-centered bias.

To study metaphor separately from other factors, we must begin with a careful consideration of the nature of metaphorical thinking. Verbrugge (Note 5) has analyzed metaphor and analogy into three parts: the topic, the vehicle to which the topic is compared, and the ground, or shared resemblance between topic and vehicle. He has found evidence that the ground-the set of implicit commonalities-plays an important role in memory for metaphors and analogies (Verbrugge, Note 5; Verbrugge \& McCarrell, Note 6). The work presented here is based on a similar but more detailed analysis: metaphors and analogies are mappings from one semantic region (the domain of origin) to another (the range of application), which convey that certain semantic relationships in the domain exist in the range. These semantic relationships are the equivalent of Verbrugge's ground: they constitute the similarity between the two entities being compared. This analysis of the ground into a set of semantic relationships will be useful in devising an objective criterion for metaphoric performance.

As an illustration, consider a sample metaphor used by Verbrugge (Note 5): “Tree trunks are straws for thirsty leaves and branches." In Verbrugge's analysis, the topic is "tree trunks," the vehicle is "straws," and the ground is "are tubes which conduct water to where it's needed" (Verbrugge, Note 5, p. $2)$. In the more detailed analysis proposed here, the metaphor is seen as a mapping from the domain of a person drinking a beverage through a straw to the range of a tree. The drinker is mapped onto the leaves and branches, the straw onto the trunk, and the beverage in its container onto water in the ground. Certain conceptual relationships are preserved in the mapping: as the drinker wants the beverage, the leaves want (are thirsty for) water; as the straw conveys the beverage, the trunk conveys the water; as the beverage nourishes the drinker, the water nourishes the leaves.

According to this analysis, a single metaphorical utterance can simultaneously convey several different similarities between the domain and the range. In fact, to be considered interesting, a metaphor or analogy must convey several ideas (Ortony 1975). Generally, the more concepts an analogy or metaphor maps from domain onto range, the better it is thought to be, provided the mapping is internally consistent, that is, provided that the relations mapped from the domain can be applied in the range without contradiction. This formulation implies that the number of concepts mapped and the relational consistency of the mapping are important in all such comparisons, whether metaphorical or analogical. The distinction between analogy and metaphor is one of function: comparisons used to serve an artistic or literary purpose are called metaphors, while comparisons used as explanatory devices are called analogies. Therefore, novelty and connotative appropriateness enter into judgments of goodness of metaphors, while analogies are more likely to be evaluated only on the number and consistency of the component mappings.

It has been shown that the ability to choose novel or appropriate metaphorical mappings increases with age (Winner, Rosenstiel, \& Gardner 1976; Kogan, Note 2). The present work focuses instead on an ability common to both analogical and metaphorical processing: the ability to preserve semantic relations during analogical mappings. A class of spatial analogies was chosen such that all three aspects-the domain, the range, and the rel- 
evant relational system-were familiar to preschool children. The question then was whether children would be able to map consistently, given these familiar materials.

Children and adults were asked to map from the domain, a human body, to the range, a concrete object. For example, a child was shown a picture of a mountain and asked, "If the mountain had a knee, where would it be?" The child responded by pointing to some point on the picture. After several different body parts had been mapped onto mountains, the child's responses were combined and a measure of consistency was computed. The set of body parts is connected by a set of transitive vertical relations: the head is above the shoulders, the shoulders above the stomach, and so on. These relations should be preserved in a good analogy. Thus, the number of vertical reversals in the range (the mountain) was the measure of performance; the lower the number of reversals, the better the performance.

In the preliminary experiment, 4-year-olds and adults performed equally well in a task in which body parts and face parts were mapped onto mountains or trees. This lack of age differences could not be entirely dismissed as a ceiling effect, for both groups performed significantly better when mapping all body parts onto one picture than when mapping each body part onto a separate picture, and there was no interaction between age and mode of mapping. It thus appeared that 4-year-olds possessed the ability to perform simple mappings.

In the present experiment, two mapping tasks were designed to be more difficult than simple body-parts mappings. In the first task, the orientation of the range picture was varied. Body parts were mapped onto trees which were right-side up, upside-down, or horizontal. Correct performance required that subjects map the terms consistently with respect to the vertical axis of the tree, and not the axis of the picture. The task required the equivalent of a mental rotation to align the up-down axis of body terms with the down-up or right-left axis of the tree. In the second task, misleading local details were added to the range pictures. The task was to map two face parts-eyes and mouth-onto mountains which had feature-like crags in the following configurations: eyes above mouth, eyes on the same level as mouth, or eyes below mouth.
Correct performance required that the eyes be placed above the mouth, regardless of the configuration of features in the picture. The subject had to ignore the local details in order to preserve the abstract set of spatial relations.

\section{Method}

Subjects

The subjects were 10 preschool children, aged $4-4$ to $5-2 ; 10$ first-grade children, aged 6-7 to 7-1; and 10 college sophomores enrolled in psychology classes at the University of Washington. Initially, 14 preschoolers, 10 first graders, and 16 sophomores were tested. Two adults and two preschool children who failed to interpret the orientation task correctly were omitted. An additional four adults and two preschoolers were randomly eliminated to reduce the number of subjects to 10 in each age group, for ease of analysis.

\section{Task}

Orientation task.-Subjects were required to map the six body parts-head, shoulders, arms, stomach, knees, and feet -onto trees in either upright, horizontal, or upside-down orientation with respect to the subject. Two modes of mapping were used: the connected mode, in which all six body. part terms were mapped onto one picture, and the discrete mode, in which the six terms were mapped one at a time onto separate pictures. The design was age (three levels) $x$ orientation (three levels) $\times$ mode of mapping (two levels).

Local-features task.-Subjects were required to map two face parts-eyes and mouth-onto mountains drawn with eyelike details either above, below, or on a level with a mouthlike detail. Only the discrete mode of mapping was used. For each configuration, subjects performed two mappings, one of the eyes and one of the mouth. These two mappings were compared to yield a single measure of the relative vertical positions of eyes and mouth. The design was age (three levels) $\times$ configuration (three levels).

\section{Stimulus Material}

There were 37 pictures: seven trees in each of three orientations, used in the orientation task; two mountains in each of three feature configurations, used in the local-features task; and 10 filler pictures of animals. Order of presentation was randomized. Sample stimuli are shown in figure 1. 
lat the eyes be
irdless of th picture. The letails in orde. atial relations

shool children, children, aged 'phomores enthe University reschoolers, 10 es were tested. l children who ation task coronal four adults andomly elimif subjects to 10 analysis.

jects were re$y$ parts-head, nees, and feet $t$, horizontal, or I respect to the ing were used: ch all six bodyone picture, and $h$ the six terms nto separate picree levels) $\times$ oriode of mapping

Subjects were parts-eyes and wn with eyelike Ir on a level with discrete mode of sh configuration, pings, one of the These two mapld a single meapositions of eyes age (three levels) ;).

$\therefore$ seven trees in ed in the orientaeach of three feathe local-features animals. Order of d. Sample stimuli
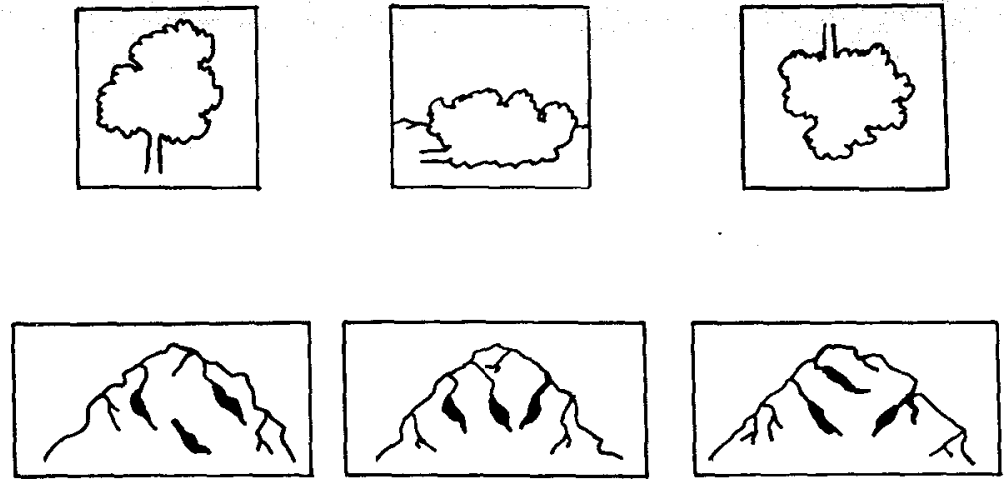

FIG. 1.-Sample stimuli. The top pictures were used in the orientation task; the bottom pictures were used in the local-features task.

\section{Procedure}

The question put to the subjects was, "If this [range object] had a [domain part], where would it be?" Children were tested individually. They were questioned orally and responded by pointing to the picture. The experimenter marked the picture at the place $(\mathrm{s})$ indicated by the child. Adults were tested in groups of about six. Their pictures were presented in booklets, with the part to be mapped printed in the corner of each picture. Adults marked their own pictures.

\section{Scoring}

For each pictured object, the vertical distance between the base of the object and the point(s) marked was measured with a ruler and recorded as a portion of the overall height of the object. (When more than one point was marked for a given response, e.g., for eyes or shoulders, the mean height of the points was used.) Then all the heights of a given mapping (e.g., body onto tree) were compared to yield the number of vertical reversals in the mapping. In connected mode, all heights came from one picture; in discrete mode, heights were compared across several pictures. A vertical reversal was defined as a reversal in the proportionate heights of two (body or face) parts between the domain (the human body or face) and the range (tree, mountain, etc.). For example, the ordering "nose, mouth, eyes, chin" contains two reversals: eyes/mouth and eyes/nose.

Interjudge agreement on number of reversals was close to perfect; only one disagreement was found when a sample of 100 responses were independently scored by a second judge.

\section{Results}

\section{Orientation Task}

Table 1 shows the mean number of reversals across age. All groups performed well; the mean number of reversals ranged from 0.6 to 0.9 reversals per mapping across age groups. There were no significant effects of age, according to a mixed-design analysis of variance. The effects of mode of mapping were significant across age, $F(1,27)=29.1, p<.01$; both adults and children performed better in connected mode than in discrete mode. The interaction between age and mode of mapping was nonsignificant. Thus, the nonsignificance of age as a main effect cannot be dismissed as a ceiling effect; at least in discrete mode, any age differences present had the opportunity to display themselves. The only significant interaction was that of age by orientation, $F(4,54)=2.7, p<.05$. This interaction apparently reflects the fact that, while

TABLE 1

Mean Numbers of Reversals in Orientation Task, by Age

\begin{tabular}{|c|c|c|c|}
\hline \multirow[b]{2}{*}{ ORIENTATION } & \multicolumn{3}{|c|}{ AGE GROUP } \\
\hline & Preschool & First Grade & Adult \\
\hline Upright: & & & \\
\hline $\begin{array}{l}\text { Connected... } \\
\text { Discrete..... }\end{array}$ & 1.0 & 0.1 & 0.3 \\
\hline Upside down: & & & \\
\hline Connected... & 0.3 & 0.3 & 0.4 \\
\hline Discrete..... & 1.3 & 0.7 & 1.6 \\
\hline Horizontal: & & & \\
\hline $\begin{array}{l}\text { Connected... } \\
\text { Discrete.... }\end{array}$ & $\begin{array}{l}0.3 \\
0.8\end{array}$ & $\begin{array}{l}0.4 \\
1.5\end{array}$ & 0.9 \\
\hline Mean......... & 0.87 & 0.60 & 0.88 \\
\hline
\end{tabular}


both groups of children made fewer reversals than adults in the two nonvertical orientations, preschoolers made larger numbers of reversal errors than adults in the standard upright orientation.

\section{Local-Features Task}

Table 2 shows the mean number of errors in each of the three local-features conditions, by age. A mixed-measures analysis of variance revealed significant effects of age, $F(2,27)=$ $5.7, p<.01$. A post hoc Scheffé test for differences between specific means revealed that the adult group produced significantly more ties and reversals than the two groups of children, whose scores did not differ significantly from each other. Adults made most errors when eyelike and mouthlike details were on the same level, reflected in part in a significant interaction between age and local details, $F(4,54)=3.3, p<.05$.

Adults appeared to be more influenced than children by the local features in the range pictures. This possibility was investigated by comparing subjects' use of all details present in the pictures-not only the eyelike and mouthlike features which were manipulated, but also the less prominent crags which were present for verisimilitude. The age differences in propensity to point to details were quite strong. All adults used details in most or all of their mappings, whereas seven out of the 10 preschoolers and five out of 10 first graders never used any details. Out of the 60 individual mappings performed by each age group, 59 of the adult mappings involved use of one or more details, as compared with 17 for first graders and seven for preschoolers.

\section{Discussion}

This task avoids the methodological difficulties described earlier: differential familiarity with the conceptual domains, dif-

TABLE 2

Mean Numbers of Reversals in Local-Features Task, by Age

\begin{tabular}{lccc}
\hline & \multicolumn{3}{c}{ AgE Group } \\
\cline { 2 - 4 } $\begin{array}{c}\text { Lonfigur } \\
\text { Contion }\end{array}$ & Preschool & First Grade & Adult \\
\hline $\begin{array}{l}\text { Eyes above mouth... } \\
\text { Eyes same level }\end{array}$ as & 0.1 & 0.1 & 0.4 \\
mouth............. & 0.1 & 0 & 0.7 \\
Eyes below mouth... & 0.2 & 0 & 0.4 \\
\end{tabular}

ferential prelearning of items, and differential interpretation of the task. The conceptual do. mains of body parts and of common physical objects are familiar even to preschool children; the mappings are not conventional metaphors that older children might have learned in advance; and the phrasing of the question makes it clear that the child is to use an analogical interpretation. Finally, there is an objective criterion for level of performance.

Under these conditions, children performed extremely well. In the orientation task, there were no significant age differences between preschoolers, first graders, and adults. In the local-features task, which did show significant age effects, children performed better than adults. It is tempting to describe the adult performance in the language often used to describe similar findings concerning children, claiming that adults showed an inability to preserve an abstract set of conceptual relations in the face of conflicting concrete details. Alternatively, one might conclude that the adults had interpreted the task in a more complex manner than the children, or that they were attempting a more artistic solution to the mapping problem, or that they strove for a more precise comparison between domain and range. The relatively poor performance of adults in this task may be an indication of the importance of factors other than simple consistency in the later development of analogical and metaphorical processing. Nevertheless, the consistency with which young children performed these tasks is surprising.

These results indicate that basic analogical ability is well developed in preschool children. This is not to say that there are no differences between adults and children in ability to use figurative language. The approach taken here emphasizes consistency of analogical application, bypassing the more creative aspects of metaphorical language. Nevertheless, these results weaken the position that young children lack metaphorical ability, and are compatible with the hypothesis that such ability is present at the outset of language use. Since no children of an intermediate age were tested, these results are also compatible with the position that metaphorical development is curvilinear, with very young children and adults showing higher erfomance than chidren in the intermediate age rango (Cardher 1974, Gardner, Kircher, Wminer, \& Perkins lois.

\section{Reference Notes}

1. Thomson, J., \& C "Daddy" (revisited) olds' overextended prehension. Paper $p$ Annual Stanford $\mathrm{Cl}$ Forum, Stanford, Cal

2. Kogan, N. Metaphori velopmental and ind Paper presented at $t$ for Research in Chi April 1975.

3. Winner, E. Can p metaphoric figures? "And Pharoah"s hear sensitivity to figurat presented at the me search in Child De 1975.

4 Winner, E., \& Rose ment of metaphoric sented in part at the Research in Child D 1975.

5. Verbrugge, R. R. T ogy. Paper present Midwestern Psy Chicago, May 1-3,

6. Verbrugge, R. R., \& inference in the co Paper presented a western Psycholog May 12,1973

\section{References}

Asch, S. E., \& Nerlo 
ifferential eptual do1 physical hool chil. ventional ight have ing of the $\mathrm{d}$ is to use $y$, there is of perfor-

dren perrientation ifferences lers, and which did dren permpting to 1 the lanir findings lat adults bstract set face of ively, one rad inter

$x$ manner 2 attemptmapping re precise ange. The Its in this ortance of icy in the ical and eless, the dren per-

c analogipreschoo are are no iildren in

The apistency of the more language. the positaphorical with the ent at the dren of an se results ition that rvilinear, s showing in the inGardner double function terms in children: an exploratory investigation. In B. Kaplan \& S. Wapner (Eds.), Perspectives in psychological theory. New York: International Universities Press, 1960.

Bloom, L. One word at a time: the use of single word utterances before syntax. The Hague: Mouton, 1973.

Bowerman, M. Semantic factors in the acquisition of rules for word use and sentence construction. In D. Morehead \& A. Morehead (Eds.), Directions in normal and deficient child language. Baltimore: University Park Press, 1976.

Carlson, P., \& Anisfeld, M. Some observations on the linguistic competence of a two-year-old child. Child Development, 1969, 40, 565-575.

Chukovsky, K. [From two to five] (M. Morton, trans.). Berkeley: University of California Press, 1968.

Gardner, H. Metaphors and modalities: how children project polar adjectives onto diverse domains. Child Development, 1974, 45, 84-91.

,Gardner, H.; Kircher, M.; Winner, E.; \& Perkins, D. Children's metaphoric productions and preferences. Journal of Child Language, 1975, 2, $1-17$

Inhelder, B., \& Piaget, J. The growth of logical thinking from childhood to adolescence. New York: Basic, 1958.

Jacobson, R. Linguistics and poetics. In T. Sebeok (Ed.), Style in language. Cambridge, Mass.: M.I.T. Press, 1960.

Ortony, A. Why metaphors are necessary and not just nice. Educational Theory, 1975, 25, 45-53.

Winner, E.; Rosenstiel, A. K.; \& Gardner, H. The development of metaphoric understanding. Developmental Psychology, 1976. 2, 289-297. 